\title{
Educação: Direito Fundamental de Todos
}

\author{
Ana Maria Severiano de Paiva ${ }^{1}$ \\ ${ }^{1}$ Universidade Severino Sombra, Programa de Pós-Graduação Stricto \\ Sensu- Mestrado Profissional em Educação Matemática, \\ anaseveriano@uol.com.br
}

Resumo: A educação ganha centralidade quando da discussão dos direitos humanos. Ao inserir a reflexão sobre o direito à educação no contexto da luta pelos direitos humanos, busco refletir sobre o processo que, tanto o Estado, quanto os sujeitos sociais devem percorrer, quando da definição de prioridades para as políticas públicas. O texto constitucional de 1988 e a LDB $n^{o}$. 9394/1996, ao definirem atribuições para o ente da federação e para as instituições escolares, abrem a possibilidade de diferentes locais - Município e Escola - para a constituição e implementação de políticas públicas que garantam o dever do Estado com educação escolar pública, prioritariamente, naquele nível que é considerado direito público subjetivo, efetivado mediante a garantia de acesso ao ensino fundamental.

Palavras-chave: Políticas públicas. Direito à educação. Escola

\section{Education: Everybody's Fundamental Right}

Abstract: Education has gained focus since the discussion concerning human rights. While inserting the reflection on the right to education in the context of the struggle for human rights, I aim to reflect on the process through which the State as well as the social subjects must go through since the definition of priorities for public policies. The constitutional text of 1988 and the LDB $n$. 9394/1996, while defining attributions for the federation and for schooling institutions, enable taking different "places" into consideration - Local authority and School - for the constitution and implementation of public policies that guarantee the duty of the State towards public school education, mainly in the level which is considered subjective public right, brought into effect by the guarantee of access to both elementary and high schooling.

Keywords: Public policies. Right to education. School.

\section{Introdução}

O artigo 26 da Declaração Universal dos Direitos do Homem, que estabeleceu o compromisso entre as Nações de assegurar educação gratuita a todos os cidadãos, representa, desde 1945, o principal eixo norteador [...] em todo o mundo. (Direitos Humanos no Cotidiano. Ministério da Justiça, 2001, p. 289)

A educação ganha centralidade quando da discussão dos direitos humanos. A ela se atribui a garantia do respeito por direitos e liberdades, de tal forma que, todos os 
indivíduos e órgãos da sociedade tenham conhecimento e possam desenvolver esforços nacionais e internacionais, não só para reconhecer, mas para garantir os direitos fundamentais do homem.

O princípio de que a educação é um direito fundamental é recente no plano jurídico. Será a partir da Segunda Guerra Mundial, através das discussões travadas no centro do Estado-Providência, que os direitos de todos os homens, dentre eles o direito à educação, passará da esfera nacional para a internacional, tornando-se responsabilidade do Estado. Paradoxalmente, encontramos-nos frente a um direito que, ao mesmo tempo, é uma obrigação do Estado e da família.

Toda pessoa tem direito à educação. A educação deve ser gratuita, pelo menos a correspondente ao ensino primário fundamental. $\mathrm{O}$ ensino primário deve ser obrigatório. $\mathrm{O}$ ensino técnico e profissional deve ser generalizado; o acesso aos estudos superiores deve estar aberto a todos, em plena igualdade, em função do seu mérito.

A educação deve visar à plena expansão da personalidade humana e ao reforço dos direitos do homem e das liberdades fundamentais e favorecer a compreensão, a tolerância e a amizade entre todas as nações e todos os grupos raciais ou religiosos, bem como o desenvolvimento das atividades das Nações Unidas para a manutenção da paz.

Aos pais pertence a prioridade do direito de escolher o gênero da educação a dar aos filhos. (Artigo 26 da Declaração Universal dos Direitos do Homem. Relatório do Desenvolvimento Humano. UNESCO, 2000, p. 15)

Compreender a história dos direitos humanos é compreender a história das lutas humanas, porque nascer com direitos básicos, assim considerados universalmente, não significa tê-los inscritos, automaticamente, na vida de todas as pessoas. Podem ser universais, mas não são universalmente aceitos. As leis, unicamente, não conseguem garantir os direitos humanos. Esses são, acima de tudo, uma prática. Têm de penetrar em todos os tipos de relação entre os homens. As declarações internacionais terão grande importância para essa questão. Ao reconhecerem a dignidade de todos os homens, considerando-os em igualdade de direitos, atribuem a esses o fundamento da liberdade e da justiça, considerando o desprezo por eles como responsável pela exclusão social, econômica, cultural e política (UNESCO, 2000).

Ao inserir a reflexão sobre o direito à educação no contexto da luta pelos direitos humanos, no plano internacional, nacional e local, busco refletir sobre o processo que tanto o Estado quanto os sujeitos sociais devem percorrer, quando da definição de prioridades para as políticas públicas.

\section{Direito à educação e direitos humanos}

A Declaração de 1948 convoca as nações a estabelecerem relações amistosas, a protegerem os direitos dos homens e as liberdades, através de um regime de direitos. Essa Declaração consagra, pela primeira vez, a "fé nos direitos fundamentais do homem, na dignidade e no valor da pessoa humana, na igualdade de direitos dos homens e das mulheres", considerando-os como uma responsabilidade mundial dos Estados. Os princípios enunciados pelas declarações de direitos humanos, principalmente a de 1948, têm sido entendidos como estatuto de lei, por terem sido reconhecidos por todos os 
Estados. Mas, para que realmente essas declarações se efetivem, é necessário que os Estados garantam esses direitos.

São numerosos os instrumentos jurídicos internacionais, após a Declaração de 1948, que se referem à necessidade de a educação se destinar a aumentar o respeito pelos direitos humanos: Declaração dos Direitos da Criança (1959); Pacto sobre Direitos Civis e Políticos e sobre Direitos Econômicos Sociais e Culturais (1966); Convenção para Eliminação de Todas as Formas de Discriminação contra as Mulheres (1979); Convenção sobre os Direitos da Criança (1989); Declaração sobre o Direito ao Desenvolvimento (1986); Conferência Mundial de Educação em Jomtiem (1990); Conferência do Rio de Janeiro (1992); Conferência de Nova Delhi (1993). A Conferência Mundial de Educação, realizada em Jomtien (1990), indica a necessidade de construção de um novo modelo de política educacional, que assegure, para todos, uma educação básica de qualidade, condição essencial para o desenvolvimento humano. (UNESCO, 2000, p.14).

Todos esses compromissos chamam a atenção para o Estado como aquele que está encarregado de, através das políticas públicas, garantir a educação como meio de efetivar o respeito por direitos humanos e liberdades fundamentais a todos os indivíduos, sem distinção de raça, sexo, língua ou religião.

Mas qual a importância de tratar a questão da garantia e ampliação do direito à educação a partir da ótica dos direitos humanos? (UNESCO, 2000, p. 14)

No preâmbulo da Declaração Universal dos Direitos do Homem (1948), é proclamado que, através do ensino e pela educação, pode desenvolver-se o respeito a direitos e liberdades. Mas, o problema fundamental em relação aos direitos do homem, hoje, não é tanto o de justificá-los, mas o de protegê-los, ampliá-los, tornando-os presentes nas políticas públicas. Trata-se de um problema não filosófico, mas político (Bobbio, 1992).

Nesse contexto, torna-se significativo pensar sobre quais são as regras e os procedimentos que influem na orientação das políticas públicas (Bobbio, 1987), principalmente quando verificamos, através de textos legais oriundos da sociedade política, a convocação da sociedade civil a reivindicar direitos, como observamos no artigo $2^{\circ}$ da Declaração Universal dos Direitos do Homem:

Todos os seres humanos podem invocar os direitos e as liberdades proclamados na presente Declaração, sem distinção alguma, nomeadamente de raça, de cor, de sexo, de língua, de opinião política ou outra, de origem nacional ou social, de fortuna, de nascimento ou de qualquer outra situação. (UNESCO, 2000, p.14)

O direito de todos os homens à educação inclui-se, hoje, na pauta das reivindicações mais significativas para a humanidade. Mais do que ir à escola, educação é ter acesso às diferentes linguagens, aos diferentes saberes. É compreender o direito à educação como um direito permanente e de todos. É com o acesso à educação, pelo caminho do direito, que se colocam em cena, para todos os homens, questões como: "A que é que todos têm direito afinal?" (UNESCO, 2000, p.19) 


\section{Município e Escola: "Locais" de Efetivação do Direito à Educação}

O texto constitucional de 1988, ao definir os municípios como entes da Federação com autonomia, com recursos e responsabilidades próprios, abre a possibilidade de organização diferenciada das políticas públicas educacionais locais, que visam à garantia e à ampliação do direito à educação. Os municípios deixam de ser unidades administrativas coadjuvantes de um Estado ou território e assumem a condição de ente federativo. No campo da educação, abre-se a possibilidade de os municípios organizarem os seus sistemas de ensino, com as seguintes incumbências, inscritas no Artigo 11 da Lei de Diretrizes e Bases (n. 9.394/96):

I - organizar, manter e desenvolver os órgãos e instituições oficiais dos seus sistemas de ensino, integrando-os às políticas e planos educacionais da União e dos Estados;

II - exercer ação redistributiva em relação às suas escolas;

III - baixar normas complementares para o seu sistema de ensino;

IV - autorizar, credenciar e supervisionar os estabelecimentos do seu sistema de ensino;

V - oferecer a educação infantil em creches e pré-escolas, e, com prioridade, o ensino fundamental, permitida a atuação em outros níveis de ensino somente quando estiverem atendidas plenamente as necessidades de sua área de competência e com recursos acima dos percentuais mínimos vinculados pela Constituição Federal à manutenção e desenvolvimento do ensino.

VI - assumir o transporte escolar dos alunos da rede municipal. (Incluído pela Lei $n^{0}$ 10.709, de 31.7.2003)

A educação como direito fundamental de todos e de cada ser humano está expresso no artigo $3^{\circ}$ e, como dever, no artigo $4^{\circ}$ da Lei de Diretrizes e Bases da Educação Nacional (n. 9.394/96). No Art. $\mathbf{5}^{\circ}$, o ensino fundamental é direito público subjetivo, devendo ser garantido pelos municípios, podendo qualquer cidadão, grupo de cidadãos, associação comunitária, organização sindical, entidade de classe ou outra legalmente constituída, e ainda, o Ministério Público, acionar o Poder Público para exigi-lo.

\subsection{O Município}

As atribuições dos municípios, para garantir o Ensino Fundamental, correspondem não somente a uma transferência formal de competências, mas refletem uma mudança sobre o papel dos poderes nos diferentes domínios da esfera pública (Uga, 1991).

Sobre a descentralização, expressa na distribuição de atribuições para os entes federativos, podemos identificar diferentes leituras. Pode significar não uma redistribuição do poder, mas um fortalecimento dos grupos hegemônicos locais no poder, contribuindo para fortalecer mais os interesses individuais que os interesses da sociedade global. (Tobar, 1991). Uma outra equivocada leitura é tomar a descentralização como um fim. Ao mesmo tempo em que se realiza fora do Estado, no seu sentido restrito, de sociedade política, a esfera pública se realiza, também, no 
interior do "Estado ampliado", ao considerar "outros locais de exercício de poder" (Uga, 1991).

Na última perspectiva de compreensão da descentralização, pode-se considerar que se contribua para aproximar os interesses da sociedade com os do poder público, alterando a natureza deste, ampliando o conceito de Estado, interferindo em concepções "tradicionais" sobre o lugar dos indivíduos, quando lutam por direitos.

O significado da descentralização será definido pela forma como se constitui historicamente o local. Poderá favorecer um processo de ampliação das bases da sociedade local, com a possibilidade de definição de "múltiplos locais de políticas e práticas" que se localizam tanto no Estado, quanto na sociedade.

A "norma jurídica" que reconfigura a relação entre os entes federativos, assim como o nível de riqueza econômica de um município, não serão, portanto, as únicas variáveis capazes de interferir nas decisões de uma administração municipal a respeito de qual política pública investir prioritariamente. Observamos que é no campo das forças políticas e das forças sociais locais que se decidem as prioridades das políticas públicas.

$\mathrm{Na}$ avaliação dos governos municipais, sobre a adesão aos programas oriundos do plano nacional, influem o cálculo dos custos e benefícios e a dimensão política dessas decisões. Dessa forma, há que se deixar como questão para reflexão não somente a adesão irrestrita às políticas federais, mas as possíveis resistências e negação à política nacional de educação (Freitas, 1998).

Em função dessas questões, as experiências práticas de políticas públicas nos municípios, necessitam ser avaliadas e ressignificadas. Principalmente em um país como o Brasil, em que as diferenças econômicas, políticas, culturais e sociais apontam muito mais para: diversidade e especificidade de cada local, de cada região; distanciamento da política federal, possibilitando construir uma política à margem da política federal.

\footnotetext{
Nós partimos do princípio de que uma política escolar sobre um território não se reduz jamais a sua simples "aplicação", mas que há, mesmo nos sistemas os mais centralizados, um processo de recontextualização para os atores locais em função das configurações sociais e das oportunidades políticas que orientam as políticas ao nível nacional e mesmo supranacional. [...] Daí ser importante estudar como se articulam, no discurso e na ação, as lógicas globalizantes e as lógicas locais. Uma tal ótica supõe uma construção do "local”. (Zanten, 2000, p.12)
}

A revalorização do local transparece através da emergência de dispositivos institucionais novos, que não somente consideram as prioridades globais, mas, em função da autonomia, reconhecem a existência de desigualdades e especificidades territoriais. Esse reconhecimento significará a possibilidade de desenvolver políticas públicas educativas adaptadas a cada município e neste a cada unidade escolar. Essa será a possibilidade de definir e implementar políticas a partir do ente federativo Município- e da instituição escolar-Escola.

Essas observações permitem afirmar que as definições do Estado no plano nacional, no confronto com as lógicas locais, devem considerar as particularidades da realidade cultural, política, social e econômica. Isso chama a atenção para o fato de que a análise das políticas públicas não pode desconsiderar a constituição histórica, política, 
econômica e cultural de cada município, por nós considerado como um dos "locais" de constituição e implantação de políticas que garantem o direito à educação.

\subsection{A Escola}

Se o município é considerado um dos "locais" para a definição de políticas, também a instituição escolar pode ser assim considerada. Não é a escola simplesmente aquela instituição que "cumpre" as decisões, as normas, mas é também a que pode interferir nas políticas públicas. Para tal, é necessário que se observe a forma como constrói o seu projeto pedagógico, como se articula com a comunidade escolar. Ou seja, como a escola, assim como o município cumpre as atribuições definidas na Lei de Diretrizes e Bases da Educação Nacional n. 9394 de 1996:

Art. 12. Os estabelecimentos de ensino, respeitadas as normas comuns e as do seu sistema de ensino, terão a incumbência de:

I - elaborar e executar sua proposta pedagógica;

II - administrar seu pessoal e seus recursos materiais e financeiros;

III - assegurar o cumprimento dos dias letivos e horas-aula estabelecidas;

IV - velar pelo cumprimento do plano de trabalho de cada docente;

$\mathrm{V}$ - prover meios para a recuperação dos alunos de menor rendimento;

VI - articular-se com as famílias e a comunidade, criando processos de integração da sociedade com a escola;

VII - informar os pais e responsáveis sobre a frequência e o rendimento dos alunos, bem como sobre a execução de sua proposta pedagógica.

VIII - notificar ao Conselho Tutelar do Município, ao juiz competente da Comarca e ao respectivo representante do Ministério Público a relação dos alunos que apresentem quantidade de faltas acima de cinquenta por cento do percentual permitido em lei.

Lendo o art. 12, observamos que a Escola vivencia um processo de reconstrução de sua identidade através de uma nova articulação com diferentes demandas e sujeitos sociais, o que lhe fornece centralidade, quando das discussões sobre a relação do Estado com a sociedade, configurando-se como um "local de decisões".

A escola e o meio local são instâncias que mantêm relação de estreita interdependência [...] não é apenas reflexo da realidade local. Existe uma autonomia relativa dos estabelecimentos escolares através das estratégias e direção da escola. (Zago, 1997, p.31-32)

É para o interior das escolas que se dirigem e se organizam as reformas e as políticas educacionais. No processo de "distribuição" de atribuições para a escola cria-se a possibilidade da emergência de novos sujeitos e de novas formas de participação da sociedade, do mesmo modo que se questionam os diferentes locais de poder, não apenas os entes federativos, mas as instituições. É nessa perspectiva de distribuição de competências que identificamos a determinação da Lei de Diretrizes e Bases da Educação Nacional $\mathrm{n}^{\circ}$ 9.394/96, em seu artigo 12, para que as escolas definam seu projeto político-pedagógico, baseado na autonomia e na participação. Isso legitima a existência de diferenças entre os estabelecimentos, através de políticas específicas. Por 
outro lado, cresce a possibilidade de ampliação da participação de diferentes sujeitos sociais nos estabelecimentos.

No plano microssociológico, isso favoreceria a implicação da família na escolarização e uma melhor responsabilidade dos estabelecimentos e dos professores quanto às exigências familiares [...]. (Zanten, 1993, p.6)

É através de um processo de abertura da escola à participação das famílias e da comunidade local que o cidadão tem possibilidades de perceber

[...] que a esfera política está por sua vez incluída numa esfera muito mais ampla, a esfera da sociedade, em seu conjunto, e que não existe decisão política que não esteja condicionada ou inclusive determinada por aquilo que acontece na sociedade civil. (Bobbio, 1986, p.156)

Cada escola está inserida no processo histórico de seu local imediato e é nesse sentido que não se pode pensar sobre ela de maneira isolada. A estrutura da instituição escolar reflete projetos e tendências dominantes, impostas pelo Estado, a cada escola, através de legislações educativas. Entretanto, essa estrutura institucional não expressa somente os projetos do Estado, vinculados à ideologia dominante, como também os reflexos das ações e intenções da sociedade civil, das expectativas, dos projetos e da cultura cívica daquela sociedade e da sua composição social (Mercado e Rockwell, 1983).

Nessa perspectiva, a instituição escolar que aglutina identidades e interesses tem papel central, uma vez que se constitui na instância na qual, de fato, se objetiva a natureza e o conteúdo da gestão e a forma da implementação das políticas educacionais nacionais nos locais. Estas, ao darem centralidade à escola, contribuem para aproximar a escola dos diferentes sujeitos (Tiramonti, 1997). Essa aproximação supõe a apropriação dos espaços de educação, no âmbito do poder local, pelos profissionais de educação e pela comunidade. Assim, colocam-se em cena os sujeitos, os sentidos e as relações que estabelecem com os locais, aqui considerados como os estabelecimentos de ensino.

Focalizar o local como sendo a escola torna-se significativo, no momento em que surge uma série de questões relacionadas à definição e redefinição de competências e de responsabilidades pertinentes aos sistemas nacionais, municipais e locais. Estas questões, ao se identificarem com o direito à educação, também se identificam, em sua essência, com a garantia de direitos iguais para todos os homens. Necessitam ser não só do conhecimento da comunidade escolar, mas ser objeto de discussão coletiva entre os diferentes sujeitos sociais, não em torno de um projeto de uma determinada escola, mas em função de um projeto de sociedade democrática, de compromissos do Estado, definindo e vinculando recursos financeiros para garantir esse direito.

Não basta, portanto, a apropriação dos artigos da Lei de Diretrizes e Bases da Educação Nacional, ou da Constituição de 1988, convocando novos sujeitos para a participação na escola. Trata-se, na realidade, de compreender o que é ser sujeito desse processo, tanto por parte de quem convoca, quanto de quem é convocado.

Não basta só olhar para os eventuais novos sujeitos e novos instrumentos de intervenção, mas para as regras de jogo com as quais se desenrola a luta política num determinado contexto histórico. (Bobbio, 1987, p.65) 
Posso considerar significativo o direito de participar, o direito de associação, identificando-os como democracia e direito, mas preciso perguntar sobre o conteúdo desse processo. Em que espaços se realiza? Quem participa? Quem decide as regras de participação? Quais são as regras? (Bobbio, 1987)

A Lei de Diretrizes e Bases da Educação Nacional n. 9394 de 1996, buscando garantir a participação de diferentes sujeitos da comunidade escolar, determina, em seu artigo $3^{\circ}$, princípios como o respeito ao "pluralismo de idéias e de concepções pedagógicas e a liberdade e apreço à tolerância". A participação é referendada pela autonomia "decretada" (Barroso, 1996) e pela flexibilidade determinada pela lei. Assim, a autonomia dá um sentido novo à função social da escola, do educador e dos sujeitos da escola.

A autonomia, que é capaz de definir também a escola como um local onde se expressam os princípios do Estado descentralizador, não é suficiente para instituir formas de autogoverno nas escolas. O que está em causa, então, não é conceder mais ou maior autonomia e sim reconhecê-la como um valor intrínseco à organização das escolas.

Por ser a escola um campo de forças, onde se confrontam e equilibram diferentes expectativas, a autonomia não poderá ser compreendida como uma ação isolada de pais, alunos, professores e gestores.

Essas preocupações, em relação ao conceito de autonomia, também se fazem com o conceito de participação, definido e associado à gestão democrática das escolas, no artigo 14 da LDB. Através deste, clama-se pela definição de um projeto pedagógico das escolas com a participação de docentes, da comunidade escolar e da comunidade local.

\footnotetext{
Art. 14. Os sistemas de ensino definirão as normas da gestão democrática do ensino público na educação básica, de acordo com as suas peculiaridades e conforme os seguintes princípios:

I - participação dos profissionais da educação na elaboração do projeto pedagógico da escola;

II - participação das comunidades escolar e local em conselhos escolares ou equivalentes.
}

Quando se chama a atenção sobre a importância da participação nas escolas, deve-se tomar cuidado para não reduzi-la à freqüência a reuniões, mas ampliá-la para o nível da ação, através do ensino e para o nível da política escolar. Dessa forma, define-se o alcance político da participação. Associar as famílias ao projeto educativo significa darlhes condição de estarem atentas às questões colocadas pelo desenvolvimento da criança, envolvê-las diretamente na definição, com os professores, das prioridades da organização pedagógica da escola. $\mathrm{O}$ aumento da participação das famílias, na política escolar, deve conduzir, necessariamente, a uma modificação das relações e procedimentos no interior da escola.

A presença de alunos, famílias e professores em conselhos e comissões que muitas vezes são puramente formais e não têm nada a dizer e/ou não exercem nenhuma influência, no nível da ação, é mais frustrante que a sua exclusão, pura e simples, do processo de tomada de decisões. Estar em espaços onde não se compreende o que é falado aumenta a distância da possibilidade de participação, cria o desejo de se afastar daquele local que demonstra o quanto não sei e, porque não sabe, diminui a possibilidade de intervir, por não compreender, por não ser ouvido. 
[...] não é possível o diálogo entre os que querem a pronúncia do mundo e os que não a querem; entre os que negam aos demais o direito de dizer a palavra e os que se acham negados deste direito [...] O diálogo se impõe como caminho pelo qual os homens ganham significação enquanto homens. (Freire, 1970, p.93)

Se a lógica que rege a participação restringir-se somente à freqüência à escola para receber boletim de notas, contribuir financeiramente ou com trabalho voluntário, o sentido político-pedagógico da participação não se construirá relacionado com a dimensão da cidadania plena. Serão criados conselhos, reuniões, assembléias, eleições, mas, sem vivência de participação, esvaziar-se-ão ao longo do processo, justificando o senso comum de que não existe interesse da comunidade. Dessa forma, o poder decisório retornará para as mãos da direção da escola.

\footnotetext{
Muitas vezes, as instituições, fazendo acreditar que estão permitindo ou até incentivando uma participação ativa, de fato a estão esvaziando de toda a sua substância. É comum ver-se as exigências de participação serem "satisfeitas" através de um processo contínuo e interminável de revisões puramente formais de estatutos, regimentos, planos e currículos, sem nenhuma repercussão real na vida da escola. Desta forma, a participação perderá todo seu significado para pais, professores e alunos. É bastante freqüente a afirmação de que os professores "não conseguem" fazer os pais participarem na vida da escola, de que os pais "não manifestam o menor interesse". A mesma queixa pode ser ouvida dos diretores, em relação à dificuldade de conseguir a participação dos professores. Em um e outro caso, não é provavelmente o interesse que está em jogo, mas a possibilidade de ter uma influência real no processo de tomada de decisões. Os pais acabam vendo confirmada a sua pressuposição que de qualquer modo a escola é dirigida por profissionais e que sua participação será sempre mais uma ilusão do que realidade. Do mesmo modo, os professores acabam se convencendo que as decisões são sempre tomadas "a priori” pela direção, e que a sua participação limita-se a ratificá-las ou, quando muito, se pronunciar diante de uma estrita faixa de opções preestabelecidas. [...] Quanto menor o grau de participação na sociedade, mais importante se torna a experiência de participação na Escola. (Horta, 1978, p.5-6)
}

Há necessidade de realizar, em conjunto com outras organizações da sociedade civil, uma discussão sobre as implicações políticas do entregar-se para a escola uma série de responsabilidades em nome da autonomia e do exercício da cidadania.

Por isso, é importante que a sociedade civil ocupe espaços como a escola, pensando-a, lutando por seus projetos, representando diferentes segmentos sociais, tornando-se uma das instituições protagonistas das transformações da sociedade. Aprofunda-se a construção da democracia ao valorizar a construção dos sujeitos, compreendendo que o próprio sujeito a ser formado é sujeito de sua formação, quando se atribui "[...] a cada um individualmente do mesmo modo como a todos os outros o direito de participar livremente na tomada de decisões coletivas" (Bobbio, 1992, p.119). 


\section{Considerações Finais}

De acordo com a Constituição de 1988, a educação considerada direito de todos visa ao preparo para o exercício da cidadania. Como condição jurídica de exercício de direitos e deveres, é construída através do vínculo entre o Estado e todos os seus membros quando lutam por direitos individuais e coletivos. Não há processo de desenvolvimento de direitos sem compromissos democráticos explícitos, em torno da participação dos diferentes sujeitos na construção de políticas e projetos pedagógicos, o que certamente implica o fortalecimento da cidadania.

Ao procedermos a uma leitura do texto da LDB n. 9.394/96, nos artigos específicos da Educação Básica, no que se refere às categorias cidadania, participação, encontraremos vários artigos sempre associando essas categorias a direito do indivíduo e dever do Estado no campo da educação. Para quem se viu à margem desses direitos pela exclusão do acesso à educação, mesmo quando presente constitucionalmente, deve-se falar muito mais em um processo de conquista da cidadania e da democratização. Uma construção ainda em processo, no sentido de que, no momento em que aquisições cidadãs e democráticas, como o direito à educação, são garantidas constitucionalmente, recomeça o trabalho de ampliação dos limites já alcançados (BOBBIO, 1987).

O que este ensaio aponta é que, para entender a política pública de educação no município, é necessário identificar as discussões internacionais sobre a garantia do direito à educação e as legislações nacionais que visam a cumprir essas determinações, definindo as atribuições dos municípios e das escolas. Mas, como variáveis deve-se identificar a história do local, e o significado que a escola tem na história de vida das pessoas. Estes são elementos fundamentais para se entender o que ali se passa em termos de política da educação e de como repercutem, no nível local, políticas definidas nacional e internacionalmente.

Será no campo das forças políticas e das forças sociais locais que se decidirão as políticas públicas educativas. Nesse sentido, a instituição de sistemas municipais e a distribuição de competências para as escolas, considerando a descentralização, a autonomia e a participação, previstas na legislação, abrem possibilidades de políticas públicas que considerem a história do local e o protagonismo dos indivíduos. Do mesmo modo que se questionam os diferentes locais de poder: o município e a escola.

Mas há uma autonomia relativa na relação entre o município e as escolas que não pode ser desconsiderada, necessitando ser reconhecida como um valor intrínseco nessa relação. Autonomia relativa, que pode ser melhor compreendida considerando elementos microssociais, tais como histórias locais e história das pessoas envolvidas no processo de formulação de políticas e de sua operacionalização.

\section{Referências Bibliográficas}

Barroso, João (org.). (1996). O estudo da escola. Portugal: Porto Ed.

Bobbio, Norberto. (1992). A era dos direitos. Rio de Janeiro: Campus.

Bobbio, Norberto.(1987). O futuro da democracia: uma defesa das regras do jogo. Rio de Janeiro: Paz e Terra.

Bobbio, Norberto. (1986). Estado, governo, sociedade: para uma teoria geral da política. São Paulo: Paz e Terra.

Mosaico - Revista Multidisciplinar de Humanidades, Vassouras, v. 1, n. 1, p. 25-35, jan./jun., 2010 
Brasil. Ministério da Educação. Lei n. 9.394, de 20 de dezembro de 1996, de Diretrizes e Bases da Educação Nacional.

Brasil. Constituição. (1988). Constituição da República Federativa do Brasil. Brasília: Senado Federal: Centro Gráfico.

Brasil. Ministério da Justiça. (2001). Direitos humanos no cotidiano. 2. ed. Secretaria de Estado dos Direitos Humanos (em colaboração com a Unesco e Universidade de São Paulo).

Freire, Paulo. (1970). Pedagogia do oprimido. Rio de Janeiro: Paz e Terra.

Freitas, Dirce Nei Teixeira. (1998). A gestão educacional na interseção das políticas federal e municipal. Revista da Faculdade de Educação, São Paulo: USP, v. 24, n. 2, jul./dez. Disponível em <http://www.scielo.br/>

Horta, José Silvério Baía. (1978). Educação e participação. Revista de Educação da Associação de Escolas Católicas. Rio de Janeiro, ano 7, n. 27, p. 3-18.

Mercado, Ruth \& Rockwell, Elsie. (1983). La escuela lugar del trabajo docente: descripciones e debates. México: DIE.

ONU (ORGANIZAÇÃO DAS NAÇÕES UNIDAS). Década das Nações Unidas para a educação em matéria de direitos humanos.Disponível em $<$ http://www.gddc.pt/pt/dh/decadaDH/dnuemdh3.htm>

Tiramonti, Guillermina. (1997). Los Imperativos de lãs políticas educativas de los 90. Revista da Faculdade de Educação, São Paulo: USP, v. 23, n. 1-2, jan.-dez. Disponível em <http://www.scielo.gov.br>

Tobar, Federico. (1991). O conceito de descentralização: usos e abusos. Revista Planejamento e Políticas Públicas. Rio de Janeiro: FIOCRUZ, n. 5, p. 31-51, jun.

Uga, Maria Alicia D. (1991). Descentralização e democracia: o outro lado da moeda. Revista Planejamento e Políticas Públicas, Rio de Janeiro: FIOCRUZ, n. 5, p. 87103 , jun..

UNESCO. (2000). O direito à educação: uma educação para todos durante toda a vida. In: Relatório Mundial sobre Educação. (2000). Portugal: Asa Editores.

Zago, Nadir. (1997). Transformações urbanas e dinâmicas escolares: uma relação de interdependência num bairro da periferia urbana. Revista Educação, Sociedade \& Culturas, Portugal, n. 7, p. 29-54.

Zanten, Henriot-van Agnès. (2000). Comparer pour comprendre: globalisation, réinterprétations nationales et recontextualisations locales des politiques éducatives neoliberales. Revue de L'Institute de Sociologie. Bruxelles (texto digitado). 